\title{
Pre-design guidelines for GFRP composite sandwich panels
}

\author{
M.R.T. Arruda ${ }^{a^{*}}$ and B. Lopes ${ }^{b}$
}

${ }^{a}$ Research Associate, CERIS - Civil Engineering Research and Innovation for Sustainability, Instituto Superior Técnico, Universidade de Lisboa, Portugal ${ }^{b}$ Phd Student, Instituto Superior Técnico, Universidade de Lisboa, Portugal

\begin{tabular}{l}
\hline A R T I C L EI N F O \\
\hline Article history: \\
Received 24 August, 2019 \\
Accepted 15 September 2019 \\
Available online \\
15 September 2019 \\
\hline Keywords: \\
Preliminary Design \\
Carrera Unified Formulation \\
GFRP Composite Sandwich \\
Panels \\
Span/Height Ratio \\
Long Term Deflection \\
Serviceability Limit States
\end{tabular}

\section{Introduction}

Recently several experimental studies concerning the creep deformation in GFRP (glass fibre reinforced polymers) structures, have been performed by several authors (Mário Garrido \& Correia, 2016; Gonilha, Barros, et al., 2014; Sá, Gomes, Correia, \& Silvestre, 2016). Some of these studies have also undertaken a numerical and sometimes an analytical simulation of a long term deflection due to creep, using Timoshenko beam theory. These studies have been taken in order to estimate deflections of GFRP beams and panels, but for a particular section type, a unique span, and always for simple supported structures. At the moment, a simple beam theory that could accurately calculate the correct shear flexibility for any given sandwich panel section, spam and type of support, is unknown. It is important to point out, that the method for calculating the shear correction factor, to be used in Timoshenko beam theory, is only valid for: i) longitudinal plane section deformation (not present in sandwich panels (Reddy, 1984); ii) for constant shear strain in the span (Timoshenko \& Young, 1965), which is not verified in uniform span loads.

\footnotetext{
* Corresponding author.

E-mail addresses: mario.rui.arruda@tecnico.ulisboa.pt (M.R.T. Arruda)
}

(C) 2020 Growing Science Ltd. All rights reserved.

doi: $10.5267 /$ j.esm.2019.9.004 
The numerical simulation of the structural behaviour of the sandwich panels with commercial software has several limitations associated with, among other things, the fact that the behaviour of the skins is rather different from the cores. This is a clear limitation of the classical Timoshenko beam theory (Timoshenko \& Young, 1965), which is only valid for uniform sections with constant longitudinal shear deformation, something which is not usually verified in composite laminated panels (Reddy, 1997). Even if a good simple beam theory is chosen, there is still an enormous debate in the scientific community, on the precise shear correction factor, to be used in composite sandwich panels, which depends largely on the type of load and supports, as referred in (D7250M-16, 2016). The current expressions have coarse assumptions (do not provide an economic and competitive design), and are only valid for simply supported beams (CNR-DT-205/2007, 2008).

An efficient alternative to avoid shear factor corrections in slabs is to express the displacement field as function $z$ and $z^{3}$, in which the resulting warping is located in the median plane, through a more realistic function (Reddy, 1984). Therefore, with this approach, it is possible to obtain further parabolic shear stresses through the thickness of the section. One possible hypothesis is based on the theory of Kant (Kant, Owen, \& Zienkiewicz, 1982) and represents a good alternative for first-order theory with Reissner-Mindlin (Reddy, 1999) at the expense of two degrees of freedom by (Pandya \& Kant, 1988) node, but still with theoretical limitations. Recently Carrera developed a unified Formulation (CUF) (Carrera, 2003), which is based on the fact that the equations of motion, boundary conditions and/or matrix of finite elements have a common standard. This standard (which was called fundamental core) expands according to the degree that is chosen to displacement field. It has been shown recently that this approach is the most complete and efficient to study various theories of sandwich panels (Carrera \& Boscolo, 2007; Carrera \& Brischetto, 2008; Ferreira et al., 2013; Neves et al., 2012), even when computing long term deformation with creep (Arruda et al., 2017).

With these recent studies, it is now possible to easily inquirer which section geometry of a given sandwich panel, provides low creep deformation. With this "indirect" controlled creep deformation, it is possible to estimate a span/height ratio, to be used in the proposed pre-design guides for structural GFRP sandwich panels. At the moment, several structural civil engineering codes and books provide pre-design guides (Brockenbrough \& Merritt, 1999; EC2, 2010; FIB, 2010; Fridley, Pollock, \& Cobeen, 2006) for "indirect" controlled deformation, but only for reinforced concrete, steel and wood structures. Concerning GFRP structures, no such code or book exist at the moment, also due to the unknown thematic in the civil engineering industry for FRPs.

\section{Objectives}

The main objective of this work is to present a recent research, concerning some preliminary design guides to be applied in GFRP composite sandwich panels, for civil engineering applications, mainly home buildings. Just like in other materials in civil engineering, these pre-design guides are based on "indirect" deflection control. This is performed using an extensive parametric analysis of: the sandwich panel materials; type of support; load levels; and geometrical properties, with the help of a high order beam theory. The adopted high order beam theory is Carrera Unified Formulation, since it correctly estimates the flexural and shear deformations, therefore, no simplified shear correction factor is needed.

It will be admitted two types of GFRP panel sections: a simple panel; and a ribs panel (Mário Garrido \& Correia, 2016). Also, three type of possible standard materials for the core will be adopted according to the industry standards (M. A. Garrido, 2016). With the above referred parametric campaign, it will be possible to assemble a pre-design guide table, in order to choose the correct height of panel including the skin thickness (its geometry), in order to "indirectly" verify the maximum long term deflections due to creep. This procedure, is indeed similar, to what is performed with other materials in structural design for civil engineering. 
The results of these analyses will be used for practical applications in the design of sandwich panels, with enormous economic and sustainable relevance for Civil Engineering. This work pretends to fill this gap in knowledge, by providing simple and clear design guidelines to be applied in classical known GFRP composite sandwich panels, more specifically in home buildings. Also these tables will produce in short and long term useful tools for the preparation of the new Eurocode 10 - FRP Composite Structures (CEN/TC250, 2017).

\section{GFRP in Civil Engineering}

The sandwich panels with composite GFRP are made of thin high strength outer layers (skins), internally filled with a lightweight material layer (core). These panels structure follows a typical basic pattern, comprising two relatively thin skins of high strength, enclosing a relatively thick and light core. Many alternative forms of sandwich construction are possible by combining different skin and core materials, therefore, enabling optimum designs to be produced for particular applications (Davalos et al., 2001). FRP materials (FRPs) have an enormous potential as construction materials presenting several advantages when compared with traditional materials: high mechanical performance, lightness, low maintenance, improved durability and increasingly competitive costs (Bakis et al., 2002). These characteristics are particularly relevant for building rehabilitation, since the use of FRPs often does not need elevation devices and introduces much lower loads over existing construction elements (M. A. Garrido, Correia, Branco, \& Sá, 2012). In terms of thermal insulation this material preserves room temperature better than any other structural material (like concrete or steel), therefore, it is ideal for using on roof tops, in order to increase the building energy efficiency, and decreasing the "Global Warming Effect" due to human comfort requirements.

The design of GFRP sandwich panels is conditioned by the deformability (which the creep contributes), and in terms of collapse, by buckling phenomena (Leong, Lars C.T. Overgaard, Thomsen, Lund, \& Daniel, 2012) and skin delamination (Reis \& Rizkalla, 2008). Recent work (Keller, 2008; Keller, Vallée, \& Murcia, 2008; Sharaf \& A., 2008) including studies at IST (M. A. Garrido, Correia, Branco, \& Keller, 2014; Gonilha, Correia, \& Branco, 2014) demonstrated the structural efficiency by enhancing polyurethane cores with lateral ribs (webs) in GFRP. Having regard to its lightness, this material is economically competitive for the construction of temporary structures in disaster/ emergency situations and in the rehabilitation of old structures. Also in terms lightness this material is ideal for being produced in developed countries and being transport by air and sea to undeveloped countries in Africa (contrary to concrete and steel structures). For example, the quasi permanent load of a GFRP panel in a home building is around 3 to $5 \mathrm{kN} / \mathrm{m}^{2}$, quite low when compared with a quasi-permanent load of a concrete slab from 8 to $10 \mathrm{kN} / \mathrm{m}^{2}$. Added to this the GFRP panels presents an excellent thermal insulation as referred before, which makes them ideal for roof tops and lateral walls in countries with harsh climates (like in Africa).

\section{CUF for GFRP Composite Sandwich Panels}

\subsection{Background of CUF}

Conventional beam theories are based on a fixed number of variables; this number is usually related to the specific problem that has to be evaluated. Euler-Bernoulli and Timoshenko models (Felippa, 2005; Timoshenko \& Goodier, 1970) have previously completely described the bending of slender beams, with three unknowns. On the other hand, thin-walled beam or torsion analysis requires more sophisticated theories with a larger number of variables (Silvestre \& Camotim, 2002a, 2002b). It can be concluded that this modelling approach is problem dependent since a beam theory is ad-hoc built to face a particular structural analysis. Therefore, there is no guarantee it can be extended to other cases. This problem and its extension to enhanced models is not straightforward (Mucichescu, 1984). 
Since 1960 the finite element method (Clough, 1960; Cook et al., 2002; Turner et al., 1956), have successfully made the use of classical beam theories much more attractive, due to improvement in computer science. The possibility of solving complex framed structures with involving thousands of degrees of freedom (DOFs) and very different boundary conditions (mechanical and geometrical) has made it possible to analyse complex problems with adequate precision. However, in the work of (Novozhilov, 1961), it was been shown that there is still an existing difficulty for obtaining a complete stress/strain field in sections with complex geometries, torsion or thin walls still. These questions remain unanswered, but can be addressed by high order beam theories. In 1997, a high order shell theory using stress finite element models, was proposed by (Pereira, 1993), in which a hierarchical formulation was presented in the thickness direction. Since 2003, Professor Erasmo Carrera proposed the Carrera Unified Formulation (CUF), applied initially in plates and shells (Carrera, 2003) and then recently extended to beams (Giunta, Belouettar, \& Carrera, 2010), in which higher-order models are obtained in its framework. The present 1D formulation has been exploited for the static analysis of compact and thinwalled structures (Carrera, Giunta, Nali, \& Petrolo, 2010). Free-vibration analyses have been carried out on hollow cylindrical and wing models (Carrera, Petrolo, \& Nali, 2011; Carrera et al., 2012). A beam model with only displacement degrees of freedom has been developed (Carrera \& Petrolo, 2012) and asymptotic-like results were obtained in (Carrera \& Petrolo, 2010). CUF is a hierarchical formulation which considers the order of the model as a free parameter (i.e., as input) of the analysis; in other words, refined models are obtained with no need for ad-hoc formulations. The CUF permits one to develop a large number of beam theories with a variable number of displacement unknowns by means of a concise notation and by referring to a few fundamental nuclei (Ferreira, Araújo, et al., 2013). Higher-order beam theories can easily be implemented on the basis of the CUF, and the accuracy of a large variety of beam theories can be established in a hierarchical and/or axiomatic vs. asymptotic sense (Carrera \& Ciuffreda, 2005). A modern form of beam theories can consequently be constructed in a hierarchical manner. The number of unknown variables is a free parameter of the problem. A 3D stress/strain field can be obtained by an appropriate choice of these variables for any type of beam problem (Carrera, Pagani, \& Petrolo, 2015): compact sections, thin-walled sections, bending, torsion, shear, and localized loadings, static and dynamic problems. Also recently CUF has been successfully applied in the field of civil engineering, more specifically in the creep deformation of sandwich panels (M. R. T. Arruda et al., 2017), shear deformations of bridge GFRP decks (M. R. T. Arruda, Castro, Ferreira, Garrido, et al., 2018), and physically non-linear analysis of steel, reinforced concrete and GFRP beams (M. R. T. Arruda, Castro, Ferreira, Martins, \& Correia, 2018).

\subsection{Fundamental Equilibrium Equations}

By admitting a set of static forces acting in an elastic body, the equilibrium, compatibility and elasticity equations governing the behaviour of that structure may be expressed as (Almeida \& Freitas, 1991):

$$
\begin{aligned}
& {[D]\{\sigma\}+\{X\}=0} \\
& \{\varepsilon\}=[D]^{t}\{u\} \\
& \{\sigma\}=[C]\{\varepsilon\}
\end{aligned}
$$

The vectors $\{\sigma\},\{\varepsilon\}$ and $\{u\}$ list the independent components of the stress $\left[\begin{array}{llllll}\sigma_{x x} & \sigma_{y y} & \sigma_{z z} & \sigma_{x z} & \sigma_{y z} & \sigma_{x y}\end{array}\right]^{t}$, strain $\left[\begin{array}{llllll}\varepsilon_{x x} & \varepsilon_{y y} & \varepsilon_{z z} & \varepsilon_{x z} & \varepsilon_{y z} & \varepsilon_{x y}\end{array}\right]^{t}$ and displacement $\left[\begin{array}{lll}u_{\mathrm{x}} & u_{\mathrm{y}} & u_{\mathrm{z}}\end{array}\right]^{t}$ fields, respectively. Geometrically linear behaviour is assumed, therefore, differential equilibrium operator $[D]$, and the differential compatibility operator $[D]^{t}$, represent linear and adjoint operators. Vector $\{X\}$ lists the body force components $\left[\begin{array}{lll}X & Y & Z\end{array}\right]^{t}$. 


$$
[D]=\left[\begin{array}{cccccc}
\partial_{x} & 0 & 0 & \partial_{z} & 0 & \partial_{y} \\
0 & \partial_{y} & 0 & 0 & \partial_{z} & \partial_{x} \\
0 & 0 & \partial_{z} & \partial_{x} & \partial_{y} & 0
\end{array}\right]
$$

For a general orthotropic material the linear elastic constitutive relation can be expressed in terms of stiffness coefficients (5), by using the adopted matrix:

$$
[C]=\left[\begin{array}{cccccc}
C_{x x} & C_{x y} & C_{x z} & 0 & 0 & 0 \\
C_{x y} & C_{y y} & C_{y z} & 0 & 0 & 0 \\
C_{x z} & C_{y z} & C_{z z} & 0 & 0 & 0 \\
0 & 0 & 0 & G_{x z} & 0 & 0 \\
0 & 0 & 0 & 0 & G_{z y} & 0 \\
0 & 0 & 0 & 0 & 0 & G_{y x}
\end{array}\right]
$$

The boundary of the structure may be subdivided into two complementary regions: the kinematic boundary (Dirichlet), $\Gamma_{u}$, in which the value for the displacement fields is prescribed and the static boundary (Neumann), $\Gamma_{t}$, where the applied forces are prescribed. It can be written:

$$
\begin{aligned}
& \left\{u_{\Gamma}\right\}=\{\underline{u}\} \text { on } \Gamma_{u} \\
& {[N]\{\sigma\}=\{t\} \text { on } \Gamma_{t}} \\
& {[D]=\left[\begin{array}{cccccc}
\partial_{x} & 0 & 0 & \partial_{z} & 0 & \partial_{y} \\
0 & \partial_{y} & 0 & 0 & \partial_{z} & \partial_{x} \\
0 & 0 & \partial_{z} & \partial_{x} & \partial_{y} & 0
\end{array}\right]}
\end{aligned}
$$

The vectors $\left\{u_{\Gamma}\right\}$ and $\{t\}$ gather the components of the prescribed displacements $\left[\begin{array}{lll}u_{\Gamma \mathrm{x}} & u_{\Gamma \mathrm{y}} & u_{\Gamma \mathrm{z}}\end{array}\right]^{t}$ and forces $\left[\begin{array}{lll}t_{x} & t_{y} & t_{z}\end{array}\right]^{t}$ on the kinematic and static boundaries, respectively. Matrix [N] lists the components of the unit outward normal vector.

$$
[N]=\left[\begin{array}{cccccc}
n_{x} & 0 & 0 & n_{z} & 0 & n_{y} \\
0 & n_{y} & 0 & 0 & n_{z} & n_{x} \\
0 & 0 & n_{z} & n_{x} & n_{y} & 0
\end{array}\right]
$$

Using all three Eq. (1), to Eq. (3) it is possible to deduce equilibrium equations in the $x, y$ and $z$ direction. The matrix $\left[K_{G}\right]$ is basically the terms of the differential static equilibrium equation of motion.

$$
\begin{aligned}
\{X\} & =\underbrace{-[D][C][D]^{t}}_{\left[K_{G}\right]}\{u\} \\
{\left[K_{G}\right] } & =\left[\begin{array}{lll}
K_{x x} & K_{x y} & K_{x z} \\
K_{x y} & K_{y y} & K_{y z} \\
K_{x z} & K_{y z} & K_{z z}
\end{array}\right] \\
K_{i i} & =-\left(\partial^{2} C_{i i} / \partial_{i} \partial_{i}+\partial^{2} G_{i j} / \partial_{j} \partial_{j}+\partial^{2} G_{i m} / \partial_{m} \partial_{m}\right) \text { diagonal terms } \\
K_{i j} & =-\left(\partial^{2} C_{i j} / \partial_{i} \partial_{j}+\partial^{2} G_{i j} / \partial_{i} \partial_{j}\right) \text { non }- \text { diagonal terms }
\end{aligned}
$$

This last Eq. (12) is useful, since it makes it easier to evaluate the stiffness terms of the global governing system when conventional finite elements (FE) are applied. 


\subsection{CUF Fundamental Nuclei}

The unified formulation will be presented and then exploited to derive the governing equations in weak forms using conventional FE (Reddy, 2004). Displacement fields are in fact obtained in a unified manner, regardless of the order of the theory, which is considered as an input of the analysis. The overcoming step, from a basic to a higher-order model, is immediate and does not require any ad hoc implementations. The beams cross-section displacement Fig. 1 is describe by the generic function $F_{\tau}$.

$$
\{u\}=[F]\{a\}
$$

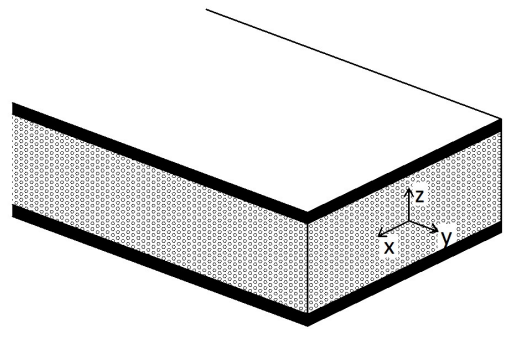

Fig. 1. Global axis of GFRP composite sandwich.

$F_{\tau}$ are functions of the cross-section coordinates $x$ and $z,\{a\}$ is the displacement vector. The choice of $F_{\tau}$ is arbitrary, which means, different base functions of any order can be taken into account to model the kinematic field of a beam above the cross-section. One possible choice is related to the use of Legendre Polynomials, used with success in the works of (Arruda et al., 2018), with CUF. The total size of the displacement vector is given by $M=(N+1) \times(N+2) / 2$, which stands for the number of terms of the expansion. For a generic frame element, the total number of degrees of freedom (DOF) is given by $3 M p$, in which $p$ is the number of the nodes by finite element (for Q2 we have $p=2$ and for Q4 is $p=4$ ). For example, in Q2 with $N=1$ there is a total of 9 generalized displacement variables in the FE formulation, with a total of 18 DOFs. The displacement variables are interpolated along the frame axis by means of the shape function $[N]$, which is a function of the $y$ coordinate.

$$
\left\{\begin{array}{l}
a_{\tau x}=a_{\tau x}(y)=\sum_{i} N_{i}(y) q_{\tau x i} \\
a_{\tau y}=a_{\tau y}(y)=\sum_{i} N_{i}(y) q_{\tau y i} \\
a_{\tau z}=a_{\tau z}(y)=\sum_{i} N_{i}(y) q_{\tau z i}
\end{array}\right.
$$

Therefore, it is possible to recover the same nodal displacement approximation, usually found in conventional FE formulations (15). The unit displacement matrix (16) can also be derived and is useful when the stiffness matrix of the governing system is being assembled.

$$
\begin{aligned}
& \{u\}=[F][N]\{q\} \\
& \Rightarrow[\psi]=[F][N]
\end{aligned}
$$

The FE model is used to approximate the problem along the $y$-axis (beam length) $N_{i}(y)$, while the expansion, $F_{\tau}(x, z)$, is used to approximate the displacement on the $z, x$-axis (cross-section). Any beam model can be derived using this formulation and classical models, such as the Euler-Bernoulli or 
Timoshenko models, can be obtained as particular cases (Timoshenko \& Young, 1965). Using index notation, it is possible to write (17), with $i$ being the node index and $\tau$ the degree approximation index:

$$
\{u\}=F_{\tau}(x, z) N_{i}(y)\left\{q_{\tau i}\right\}
$$

By means of the Galerkin weight method (Hughes, 2003), it is possible to develop the governing system of the CUF formulation, in which the static differential equilibrium condition is enforced in the following weighted residual form:

$$
\int[\psi]^{t}([D]\{\sigma\}+\{X\}) d V=0
$$

To mobilize boundary terms, the first member of Eq. (18) is integrated by parts, leading to all equilibrium conditions in the domain and boundary, as can be found in (M. R. T. Arruda et al., 2017). After all integration procedures, it is possible to rewrite the governing system in terms of matrix formulation, in which: [ $\left.\mathbb{K}_{e}\right]$ is the stiffness operator; $\{q\}$ is the depended nodal displacement vector; $\left\{Q_{m}\right\}$ is the uniform load vector; $\left\{Q_{t}\right\}$ is the line load vector; and $\left\{Q_{\Gamma \mathrm{u}}\right\}$ is the nodal load vector. The global governing system is obtained, by enforcing that the adjacent elements share the same boundary displacement along the shared edge. The assembly procedure is based on the elementary contributions, typical in classical FE models (M. R. T. Arruda et al., 2017).

$$
[\mathbb{K}]\{q\}=\left\{Q_{m}\right\}+\left\{Q_{t}\right\}+\left\{Q_{\Gamma u}\right\}
$$

It is then possible to write the fundamental symmetric nucleus for beams (Carrera et al., 2011) using the following conditions:

$$
\begin{aligned}
& \text { Diagonal Terms }(x, z) \text { with } n \neq m \neq y \\
& \begin{aligned}
\mathbb{K}_{n n}^{\tau s i j}=C_{n n} \int & F_{\tau, n} F_{s, n} d \Omega \int N_{i} N_{j} d y+G_{m n} \int F_{\tau, m} F_{s, m} d \Omega \int N_{i} N_{j} d y \\
& +G_{y n} \int F_{\tau} F_{s} d \Omega \int N_{i, y} N_{j, y} d y
\end{aligned}
\end{aligned}
$$

Diagonal Terms $(y)$ with $n=y ; m \neq k \neq y$

$$
\begin{aligned}
\mathbb{K}_{n n}^{\tau s i j}=G_{m n} \int & F_{\tau, m} F_{s, m} d \Omega \int N_{i} N_{j} d y+G_{k n} \int F_{\tau, k} F_{s, k} d \Omega \int N_{i} N_{j} d y \\
& +C_{n n} \int F_{\tau} F_{s} d \Omega \int N_{i, y} N_{j, y} d y
\end{aligned}
$$

Non-Diagonal Terms $(x, z)$ with $n \neq m \neq y$

$$
\mathbb{K}_{n m}^{\tau s i j}=C_{n m} \int F_{\tau, n} F_{s, m} d \Omega \int N_{i} N_{j} d y+G_{n m} \int F_{\tau, m} F_{s, n} d \Omega \int N_{i} N_{j} d y
$$

Non-Diagonal Terms $(y)$ with $n \neq y ; m=y$

$$
\mathbb{K}_{n m}^{\tau s i j}=C_{n m} \int F_{\tau} F_{s, n} d \Omega \int N_{i, y} N_{j} d y+G_{n m} \int F_{\tau, n} F_{s} d \Omega \int N_{i} N_{j, y} d y
$$

\subsection{Approximation Functions}

Legendre polynomials have already been proposed by other authors to simulate multilayer structures, with high-order theory in laminated composite plates. The first tests were carried out by (Carrera, Cinefra, Petrolo, \& Zappino, 2014), in which a clear advantage comes from the fact that allows one to use a LW theory, while avoiding the inclusion of constrain equations to impose $C_{z}^{0}$ requirements. This type of functions were also used in non-conventional FE formulation (M. R. Arruda \& Castro, 2011), to simulate plate behaviour, in which the stability of the governing system was always assured, even for higher degrees of approximation. The approximation functions may be defined by: 


$$
\begin{array}{cc}
F_{0}(\xi, \eta)=P_{0}(\xi) \times P_{0}(\eta) & F_{4}(\xi, \eta)=P_{1}(\xi) \times P_{1}(\eta) \\
F_{1}(\xi, \eta)=P_{1}(\xi) \times P_{0}(\eta) & F_{5}(\xi, \eta)=P_{0}(\xi) \times P_{2}(\eta) \\
F_{2}(\xi, \eta)=P_{0}(\xi) \times P_{1}(\eta) & \vdots \\
F_{3}(\xi, \eta)=P_{2}(\xi) \times P_{0}(\eta) & \vdots
\end{array}
$$

Complete sets of orthonormal Legendre polynomials are used to define the approximation bases. The generation and manipulation of such functions, is fully described in (Pereira \& Freitas, 1996a, 1996b; Spiegel \& Liu, 1999). The Legendre polynomials can be defined using the Rodriguez equation (22).

$$
P_{n}(\xi)=\frac{1}{2^{n} n !} \times \frac{d^{n}}{d \xi^{n}}\left(\xi^{2}-1\right)^{n} \lambda_{n} \quad \text { with } \quad \lambda_{n}=\sqrt{\frac{2 n+1}{2}}
$$

One of the main advantages of using these polynomials is the possibility of avoiding any numerical integration scheme for linear analysis. Therefore, it is possible to define analytical expressions (if the cross section has only one layer; or in the case of multilayer, it is required to be symmetric), for all structural operators, even for cases where orthogonality is not presented. The properties of Legendre polynomials can be exploited in the work of (Arruda et al., 2018; Pereira \& Freitas, 1996a):

\subsection{Applied Load}

In this work uniform loads are applied all through the span of the beam, and always on the top of the beam (Carrera et al., 2014), therefore, the uniform load can be written in this particular case as (23). If a load is directly applied in a nodal point, its equivalent force load can be found in the work of Carrera et al 2010 (Carrera et al., 2010).

$$
Q_{n}^{\tau i}=\int F_{\tau}(x, z=h / 2) N_{i}(y) q_{n}(x, y) d x d y \quad \text { in which } \quad q=\left[\begin{array}{lll}
0 & 0 & -q_{z}
\end{array}\right]
$$

\subsection{Integration of the CUF Nuclei with ESL}

A particular case of implementing CUF for an ESL, can be deduced using an integration piecewise in (24), and in Eq. (25) for RIBBS. These integrals can be derived by observing Fig. 2.

$$
\begin{aligned}
& C_{i j}^{e q} \int F_{\tau} F_{S} d \Omega=C_{i j}^{c o r e} \int_{-h / 2}^{h / 2} \int_{-b / 2}^{b / 2} F_{\tau} F_{S} d \Omega+C_{i j}^{G F R P}\left(\int_{-h_{t} / 2}^{h_{t} / 2} \int_{-b / 2}^{b / 2} F_{\tau} F_{S} d \Omega-\int_{-h / 2}^{h / 2} \int_{-b / 2}^{b / 2} F_{\tau} F_{s} d \Omega\right) \\
& C_{i j}^{e q} \int F_{\tau} F_{S} d \Omega=C_{i j}^{c o r e} \int_{-h / 2}^{h / 2} \int_{-b / 2}^{b / 2} F_{\tau} F_{S} d \Omega+C_{i j}^{G F R P}\left(\int_{-h_{t} / 2}^{h_{t} / 2} \int_{-b_{t} / 2}^{b_{t} / 2} F_{\tau} F_{S} d \Omega-\int_{-h / 2}^{h / 2} \int_{-b / 2}^{b / 2} F_{\tau} F_{S} d \Omega\right)
\end{aligned}
$$

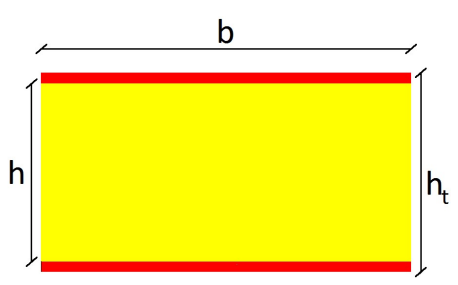

(a)

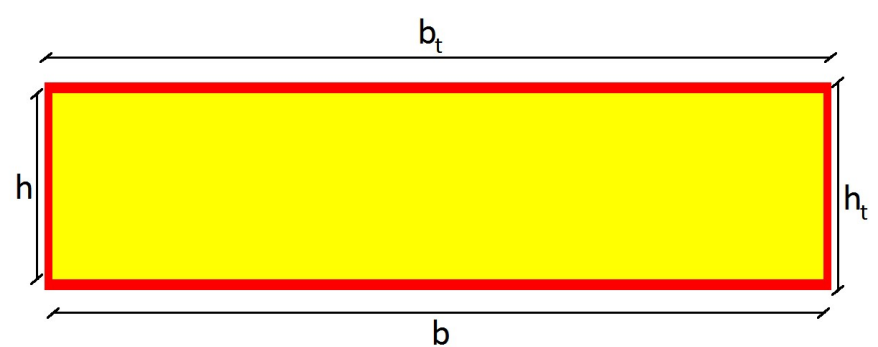

(b)

Fig. 2. Global axis of GFRP composite sandwich, a) simple panel, b) ribs panel 


\section{Long Term Deflections}

Equivalent to implement creep deformation in CUF, the relationship between stresses and strains was considered to be as:

$$
\begin{aligned}
& \{\sigma\}=[C]\left\{\varepsilon_{e}\right\}=[C]\left(\{\varepsilon\}-\left\{\varepsilon_{c}\right\}\right) \\
& \left\{\varepsilon_{c}\right\}=\varphi\left\{\varepsilon_{e}\right\}
\end{aligned}
$$

In this Eq. (26), the elastic strain $\left(\varepsilon_{e}\right)$ is considered to depend linearly on the stress level $(\sigma)$ through a stiffness matrix $[C]$, and is given by the difference between the total long-term strain $(\varepsilon)$ and the creep strain $\left(\varepsilon_{c}\right)$ (Zienkiewicz \& Taylor, 2000). The creep strain was considered to depend on the elastic strain through the application of creep coefficients $(\varphi)$ (Mase \& Mase, 1999). Such coefficients are material dependent, and provide a time-dependent measure of the magnitude of creep deformation in relation to the elastic (instantaneous) deformation in the material. Thus, by applying the Galerkin method described in equation (18), it is possible to enforce the differential equilibrium condition using creep strains as:

$$
\begin{aligned}
& \int[\psi]^{t}\left([D][C]\left\{\varepsilon_{e}\right\}+\{X\}\right) d V=0 \\
& \int[\psi]^{t}\left([D][C]\left(\{\varepsilon\}-\left\{\varepsilon_{c}\right\}\right)+\{X\}\right) d V=0
\end{aligned}
$$

A new imposed creep strain appears in the form of an equivalent load (equation (29)), and since this equivalent load is proportional to the elastic tensor (Eq. (30)).

$$
\begin{aligned}
& \Rightarrow\left\{Q_{c}\right\}=\int[B]^{t}[C]\left\{\varepsilon_{c}\right\} d V \\
& {\left[C_{c}\right]=[C(\varphi)]}
\end{aligned}
$$
(32).

It is possible to modify equation into Eq. (28) and Eq. (31), and write a new governing system Eq.

$$
\begin{aligned}
& \Leftrightarrow \int[B]^{t}\left[C_{c}\right][B] d V\{q\}=\int[\psi]^{t}\{X\} d V+\int[\psi]^{t}[N]\{\sigma\} d \Gamma_{\sigma}+\int[\psi]^{t}[N]\{\sigma\} d \Gamma_{u} \\
& {\left[\mathbb{K}_{C}\right]\{q\}=\left\{Q_{m}\right\}+\left\{Q_{t}\right\}+\left\{Q_{\Gamma u}\right\}}
\end{aligned}
$$

In this work, the composite creep modelling (CCM) approach, which entails an equivalent stiffness methodology that has been proposed in (Garrido et al., 2014) for simple panels and in (Mário Garrido et al., 2016) for panels with ribs, was adopted for the calculation of the long term displacements due to creep. The CCM approach considers creep in sandwich panels as a result of creep of its individual materials/components. Predictions of a sandwich panel's creep response are thus obtained by considering the viscoelastic increase of the constituent materials' deformations as time-dependent reductions of their stiffness or elastic moduli, and using them as input in an appropriate model of the panel's structural behaviour. These reductions may be used to affect the elastic stiffness moduli of the materials, as given by the following equations for the axial $\left(E_{\mathrm{ij}, \mathrm{c}}\right)$ and shear $\left(G_{\mathrm{ij}, \mathrm{c}}\right)$ moduli:

$$
E_{\mathrm{ij}, \mathrm{c}}(t)=\chi_{\mathrm{E}}(t) \times E_{i j}=\frac{E_{i j}}{1+\varphi_{E}(t)}
$$




$$
G_{\mathrm{ij}, \mathrm{c}}(t)=\chi_{\mathrm{G}}(t) \times G_{i j}=\frac{G_{i j}}{1+\varphi_{G}(t)}
$$

\section{Methodology Used for the Pre-Design Guides}

\subsection{Initial Considerations}

The first attempts to assemble a pre-design guideline, was performed using several blind parametrizations, in which an optimal solution is calculated according to a similar procedure described in (M. Garrido, Madeira, Proença, \& Correia, 2019). The adopted materials, spam and section geometry are described in Table 1 and Table 2 , and these lead to a total combination of $5^{9}=1.953 .125$ cases. In the end it was not possible to achieved an efficient solution that could be compared with the classical guidelines found in the pre-design of reinforced concrete, steel and wood structures. Therefore, a different optimal solution was searched in which adopted span/height ratio is at least smaller than the one provided by classical structural materials. It is then possible to adopt a span/height ratio that would be competitive with other materials in civil engineering.

\subsection{Parametrized Sections}

Two type of sections were adopted, concerning know geometries provided by GFRP sandwich panels manufacturers in the civil engineering industry (Garrido, 2016). The first section is a classical panel, with a top and bottom GFRP (only flanges) skin and a core in the middle as presented in Fig. 3 a). The second a close box GFRP skins (webs and flanges) with also a confined core in the middle as depicted in Fig. 3 b).

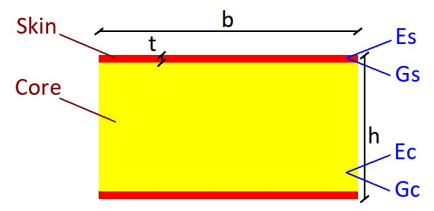

(a) Panel

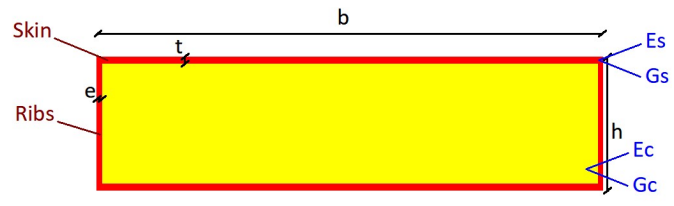

(b) Panel with ribs

Fig. 3. Adopted sections for pre-design guidelines

\subsection{Adopted Materials}

\subsubsection{GFRP Skins}

The variability of GFRP properties in the industry is massive (Clickhouse, 2014), and recently it was found out that its creep behaviour may be even bigger (Mário Garrido, Correia, Keller, et al., 2016) than the one assumed by the manufactures. Using also some information reported in the Italian FRP standard (CNR-DT-205/2007, 2008), it was possible to estimate the coefficients of creep due to longitudinal and shear deformations, for an elapsed time of 50 years. In structural design codes, it is possible to assume that the life time expectancy of a given structure is 50 years, without any external intervention or rehabilitation (Ghali, Favre, \& Elbadry, 2018). Taking in to account all of this information, it was considered an average low values for the elastic properties, and an average high values for the creep effect in the GFRP Table 1. With these simplifications, it is expected that the real deformation, will always be smaller than the numerical one, providing some safety factor for the structural designer.

Table 1. Adopted GFRP elastic and creep properties

\begin{tabular}{ccccc}
\hline$E_{S}[\mathrm{MPa}]$ & $G_{S}[\mathrm{MPa}]$ & $v[-]$ & $\phi_{E S}(50$ years $)[-]$ & $\phi_{G S}(50$ years $)[-]$ \\
\hline 30000 & 2500 & 0.31 & 0.67 & 2.0 \\
\hline
\end{tabular}




\subsubsection{Foam Core}

The variability of the foam core is bigger than the one in GFRP skins, as reported in the work of (Mário Garrido et al., 2016), even with low ambient temperature variation. Even the manufacture properties of the foam core in some cases present a high uncertainty (Airex, 2016). This lead to some authors proposing different elastic and creep properties for the material of the foam core (Mário Garrido \& Correia, 2016). Taking into account the variability of the foam core properties, due to its fabrication unpredictability in the industry, is was admitted an existence of three type of foam cores named: $1^{\text {st }}$ SoftCore, based on standard polyurethane foam, since it is one of the most flexibles; $2^{\text {nd }}$ NormalCore, based on commercial polyurethane terephthalate foam, to simulate a more rigid core foam; $3^{\text {rd }}$ a HardCore, based on wood balsa, to model a core foam with almost no creep effect. Their properties are presented in Table 2, and again are low average values for the elastic parameters, and high average values for the creep.

Table 2. Adopted core foam elastic and creep properties.

\begin{tabular}{lccccc}
\hline Foam Core Material & $E_{C}[\mathrm{MPa}]$ & $G_{C}[\mathrm{MPa}]$ & $v[-]$ & $\phi_{E c}(50$ years $)[-]$ & $\phi_{G C}(50$ years $)[-]$ \\
\hline SoftCore (PUR) & 20 & 10 & 0.3 & 6 & 6 \\
NormalCore (PET) & 40 & 20 & 0.3 & 0.5 & 0.5 \\
HardCore (Balsa) & 100 & 50 & 0.3 & 0.2 & 0.2 \\
\hline
\end{tabular}

\subsection{Load Distribution Behaviour}

As known in structural engineering, slabs tend to distribute loads in two plane directions (Ghali \& Nevillle, 1997). In this work, due to the orthotropic behaviour, and the connections between panels and supports being limited, it is assumed that the panel only distributes loads in one direction Fig. 4. Therefore, it will be expected that the calculated vertical displacements, are smaller than the real ones, providing some safety factor for the structural designer.

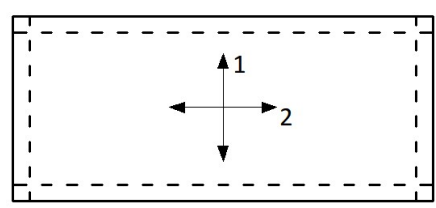

(a) Real Case

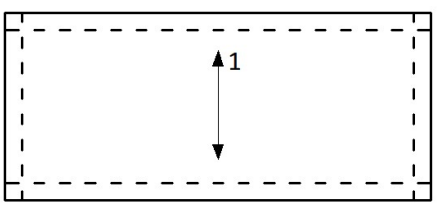

(b) Assumed behaviour (more flexible)

Fig. 4. Load distribution behaviour.

\subsection{Assumed Loads}

All the assumed loads are according to $(\mathrm{EC} 1,2002)$, relative to home buildings in conjunction with Europe structural codes. According to these structural codes, the maximum vertical displacement in beams and slabs, is computed using a quasi-permanent load combination:

- Since the section of the GFRP panel is not known initially it was assumed a self-weight of $0.5 \mathrm{kN} / \mathrm{m}^{2}$ (Clickhouse, 2014). This value is clearly above the average value of a typical GFRP composite sandwich panels, therefore, it is expected once again, that the calculated deflection values are higher than the real ones, providing some safety factor for the structural designer.

- For the permanent load, two types were used: the $1^{\text {st }}$ without the direct load of interior walls in the panel slab (these would load on a nearby beam), as depicted in Fig. 5 a), with a standard value of $1.5 \mathrm{kN} / \mathrm{m}^{2} ; 2^{\text {nd }}$ with the direct load of interior walls in the panel slab, as presented in Fig. $5 \mathrm{~b}$ ), with a standard value of $(1.5+2.0) \mathrm{kN} / \mathrm{m}^{2}$.

- For the live load, the standard value of $2.0 \mathrm{kN} / \mathrm{m}^{2}$ is adopted, with a quasi-permanent reduction factor of 0.3 . 
For the $1^{\text {st }}$ and $2^{\text {nd }}$ case this would give a total load $2.6 \mathrm{kN} / \mathrm{m} 2$ and $4.6 \mathrm{kN} / \mathrm{m}^{2}$ respectively, as demonstrated in (35) and (36). By comparing with a concrete slab, just the $1^{\text {st }}$ case would give a value above $7.0 \mathrm{kN} / \mathrm{m}^{2}$.

$$
\begin{aligned}
& q_{\text {quasi_permanent }}=p_{\text {self_weight }}+p_{\text {permanent_load }}+0.3 \times p_{\text {live_load }}=2.6 \mathrm{kN} / \mathrm{m}^{2} \\
& q_{\text {quasi_permanent }}=p_{\text {self_weight }}+p_{\text {permanent_load }}+0.3 \times p_{\text {live_load }}=4.6 \mathrm{kN} / \mathrm{m}^{2}
\end{aligned}
$$

The first parametric studies, concluded that the use of a simple panel with loads from interior walls is not competitive in terms of ration span/height when compared with concrete slabs Fig. 5 (a). Therefore, it was admitted, that when interior load walls are directly on the slab, then a panel with ribs is necessary Fig. 5 (b).

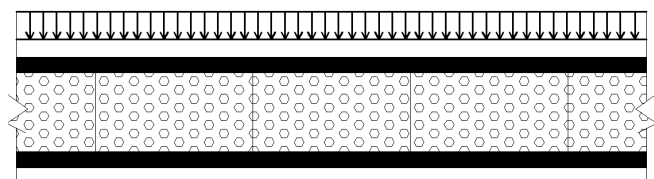

(a) $1^{\text {st }}$ case with a simple panel

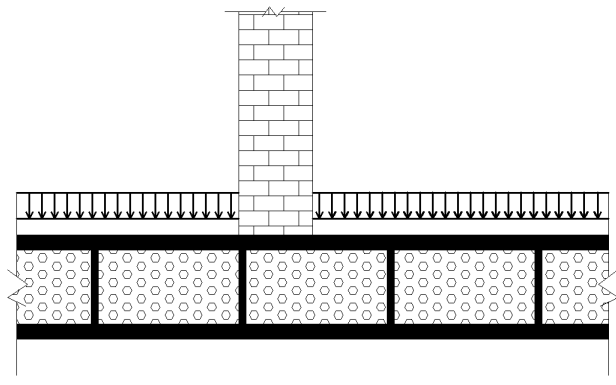

(b) $2^{\text {nd }}$ case with ribs panel

Fig. 5. Type of loads assumed.

\subsection{Chosen Geometry}

Since the design load is in units $\mathrm{kN} / \mathrm{m}^{2}$, the value of the width is not important, therefore, common values in the industry were used for the geometry of simple panel and ribs panel.

- In a simple panel, the width $b=250 \mathrm{~mm}$ is assumed, since it is a standard commercial geometry Fig. 6 a). A minimum of $5 \mathrm{~mm}$ is adopted for the skin thickness, since it is a standard value given by the industry manufactures.

- In a ribs panel, the width is a little bigger $b=500 \mathrm{~mm}$, to assume a bigger shear lag effect, that may increase the shear deformation. Again this is a standard commercial geometry Fig. 6 b).

- The ribs thickness is proportional to the skin thickness $e=70 \% t$, leaving the only unknown variables in the panel: the height and the thickness of the skin. Also a minimum of $5 \mathrm{~mm}$ is adopted for the skin thickness, since it is a standard value given by the industry manufactures.

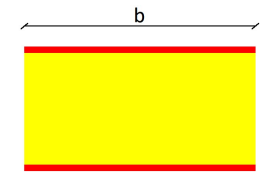

(a) Simple panel

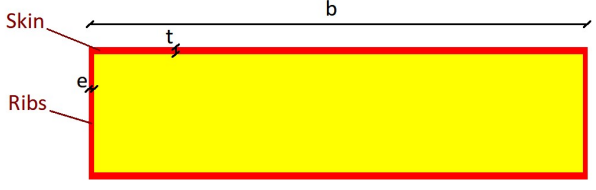

(b) Ribs panel

Fig. 6. Type of loads assumed.

\subsection{Adopted Supports}

Since in the pre-design phase, the geometry of the support is unknown, it is admitted a line support through its transversal direction. This type of support is clearly not real, as demonstrated in Fig. 7, but provides a more flexible solution, therefore, once again providing some safety factor for the structural designer. 


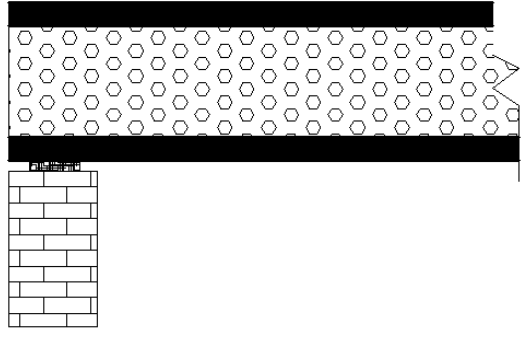

(a) Real Case

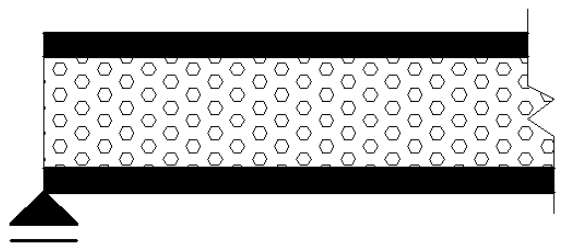

(b) Assumed geometry

Fig. 7. Type of support geometry.

Again since in the pre-design phase, the longitudinal span type is not known, the 4 classical simplified support conditions are admitted, as presented in Fig. 8. These are more than enough to estimate a vertical displacement, with uniform vertical loads in the span.

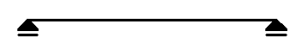

a) Pinned-Pinned

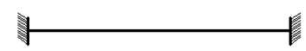

b) Fixed-Fixed

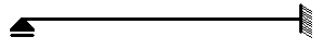

c) Fixed-Pinned

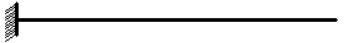

d) Cantilever

Fig. 8. Type of beam support conditions.

\subsection{Chosen Pre-Design Guides}

In conventional beams, the span/height ratio is fixed, being the rest of the geometry a function of the stress level, during the final design phase. Usually the level of deflection is fixed according to the country's structural codes (37), in this work the quasi-permanent limit is used according to Eurocode 1 $(\mathrm{EC} 1,2002)$. Since in this work the CCM is used, the creep effect is enclosed in the total effect (38).

$$
\begin{aligned}
& \delta_{\text {vertical }}^{\text {CUF }}=\delta_{\text {vertical }}^{\text {elastic }}+\delta_{\text {vertical }}^{\text {creep }} \leq \delta_{\max }=\frac{L_{\text {span }}}{250} \\
& \delta_{\text {vertical }}^{\text {CUF }}=\delta_{\text {vertical }}^{\text {elasticteep }} \leq \delta_{\max }=\frac{L_{\text {span }}}{250}
\end{aligned}
$$

When using Principal of Virtual Displacements in beams uniformly loaded with low shear deformation (39), it's easy to fix the span/height ratio, since these remain constant through the application of cubic root (39). But when shear deformation is high, this simplification is no longer possible for beams with uniform load through the span (40).

$$
\begin{aligned}
& \text { 1. } \delta=\int \frac{M \bar{M}}{E I} d x \leq \frac{L_{\text {span }}}{250} \Rightarrow \alpha \frac{L_{\text {span }}}{h_{\text {section }}} \leq \sqrt[3]{\text { cte }} \\
& \text { 1. } \delta=\int\left(\frac{M \bar{M}}{E I}+\frac{V \bar{V}}{G A_{c}}\right) d x \leq \frac{L_{\text {span }}}{250} \Rightarrow \alpha\left(\frac{L_{\text {span }}}{h_{\text {section }}}\right)^{3}+\beta\left(\frac{L_{\text {span }}}{h_{\text {section }}}\right) \leq \text { cte }
\end{aligned}
$$

But for GFRP composite sandwich panel it is even more difficult, since it is also necessary to inquirer the increase of thickness of the GFRP skin, due to these provide extra bending stiffness. Therefore, the previous equations are not possible to apply directly to GFRP sandwich panels, and a rethinking is necessary for the pre-design guides. To solve this problem, a simplification is performed, in order to eliminate these extra variables during the pre-design phase: $1^{\text {st }}$ it is admitted that a single constant $\mathrm{span} /$ height ratio is fixed for a given material section; $2^{\text {nd }}$ when performing the verification (39), if this is not achieved then only the thickness of the core is increased; $3^{\text {rd }}$ the level of span/height ratio is fixed according to values that are competitive when comparing with conventional beams in civil engineering. 


\section{Deflection Control}

\subsection{Pre-Design Guideline Table}

After running several examples, with different: foam core materials, load levels, type of support and type of sections, using the restriction in equation (38), the Table 3 was assembled. It was limited to a maximum span of 10.0 meters, because of its constraint for bigger spans in home buildings, due to high vibrations.

Table 3. Adopted span/height ratio, for indirect control of deformation due to creep.

\begin{tabular}{|c|c|c|c|c|c|c|c|c|c|c|c|}
\hline \multirow{2}{*}{\multicolumn{2}{|c|}{$\begin{array}{l}\text { Minimum thickness of the skin } \\
{[\mathrm{mm}] \text { vs allowed span length }} \\
{[\mathrm{mm}]}\end{array}$}} & \multicolumn{5}{|c|}{ Simple Panel } & \multicolumn{5}{|c|}{ Panel with ribs } \\
\hline & & $\mathbf{L} / \mathbf{h}$ & 5 & 10 & 15 & 20 & $L / h$ & 5 & 10 & 15 & 20 \\
\hline \multirow{3}{*}{ Pinned-Pinned } & SoftCore & 20 & - & $\leq 2000$ & $\leq 3000$ & $\leq 4000$ & 25 & - & $\leq 4000$ & $\leq 8000$ & $\leq 10000$ \\
\hline & NormalCore & 30 & $\leq 4000$ & $\leq 9000$ & $\leq 10000$ & - & 30 & $\leq 3000$ & $\leq 9000$ & $\leq 10000$ & - \\
\hline & HardCore & 35 & $\leq 3000$ & $\leq 7000$ & $\leq 10000$ & - & 33 & $\leq \mathbf{2 0 0 0}$ & $\leq 4000$ & $\leq 7000$ & $\leq 10000$ \\
\hline \multirow{3}{*}{ Fixed-Fixed } & SoftCore & 25 & - & $\leq \mathbf{2 0 0 0}$ & $\leq 3000$ & $\leq 4000$ & 35 & $\leq 5000$ & $\leq 10000$ & - & - \\
\hline & NormalCore & 50 & $\leq 7000$ & $\leq 10000$ & - & - & 50 & $\leq 3000$ & $\leq 9000$ & $\leq 10000$ & - \\
\hline & HardCore & 55 & $\leq 7000$ & $\leq 10000$ & - & - & 55 & $\leq 3000$ & $\leq 8000$ & $\leq 10000$ & - \\
\hline \multirow{3}{*}{ Pinned-Fixed } & SoftCore & 20 & - & $\leq 2000$ & $\leq 3000$ & $\leq 4000$ & 30 & $\leq 3000$ & $\leq 10000$ & - & - \\
\hline & NormalCore & 40 & $\leq \mathbf{5 0 0 0}$ & $\leq 10000$ & - & - & 40 & $\leq \mathbf{2 0 0 0}$ & $\leq 7000$ & $\leq 10000$ & - \\
\hline & HardCore & 45 & $\leq \mathbf{5 0 0 0}$ & $\leq 10000$ & - & - & 45 & $\leq 2000$ & $\leq 5000$ & $\leq 9000$ & $\leq 10000$ \\
\hline \multirow{3}{*}{ Cantilever } & SoftCore & 9 & - & $\leq 2000$ & $\leq 3000$ & $\leq 4000$ & 11.5 & - & $\leq 4000$ & $\leq 8000$ & $\leq 10000$ \\
\hline & NormalCore & 13.5 & $\leq 4000$ & $\leq 9000$ & $\leq 10000$ & - & 13 & $\leq 3000$ & $\leq 9000$ & $\leq 10000$ & - \\
\hline & HardCore & 15.5 & $\leq 3000$ & $\leq 7000$ & $\leq 10000$ & - & 14.5 & $\leq 2000$ & $\leq 4000$ & $\leq 7000$ & $\leq 10000$ \\
\hline
\end{tabular}

Observing Table 3, it is possible to choose a given span length, and point a $\mathrm{L} / \mathrm{h}$ ratio and skin thickness, in order to "indirectly" control the creep deformation, and therefore, choosing a valid pre-design section to be used during the final design phase. It is also important to point out, that a simple panel with SoftCore is not recommend with spans greater than 4.0 meters, due to its high creep deformation. Also with Softcore in the simple panel, a minimum of $10 \mathrm{~mm}$ is required in the thickness of the skin. It is important to point out also, that these pre-design values, are only to be used during an initial structural pre-design phase. A deep structural analysis is recommended in order to verify all aspects of ultimate and service load according to the new Eurocode 10 (CEN/TC250, 2017).

\subsection{Important Remark for the Simplified Expression}

It is even possible to simplify a bit more Table 3, when closely observed. In this case, for normal spans in home buildings $(<9000 \mathrm{~mm})$ and admitting a NormalCore at least, it is possible to use a span/height ratio $L_{\text {span }} / h_{\text {section }}=30$, with a skin thickness of $t=10 \mathrm{~mm}$. This is possible for simple panel (without loads from interior walls) and ribs panel (with loads from interior walls), admitting that all the spans are conservatively simply supported.

\section{Case Study}

Next a simple four span slab model, usually found in home buildings, is pre-design with a classical concrete slab, and with a GFRP composite sandwich panels, in order to compare solutions. For the concrete slabs, the table $7.4 \mathrm{~N}$ from $(\mathrm{EC} 2,2010)$ is used, but for the GFRP panel the purposed Table 3 is adopted. For the GFRP panels, it is admitted the possibility of existing loads from interior walls, in some sections of the home building. For the simple panel, a foam core PET is chosen (normal core), but for the ribs panel a PUR foam core (SoftCore) material is adopted. The PUR foam core was chosen with the ribs panel, to show the reader the most unfavourable solution, therefore, the highest section height needed. Which means in the ribs panel, if a foam core PET or Balsa is adopted, then section height is clearly lower than the one presented in this example, providing an even more competitive solution against the concrete slab. The pre-design section height is defined for each span separately (Fig. 9), then the thickest section height and skin thickness is adopted for both concrete slab and GFRP panel (Fig. 10). To properly visualize the difference between the thickness of the concrete slab and the GFRP panel, the vertical scale was increased 10 times. 


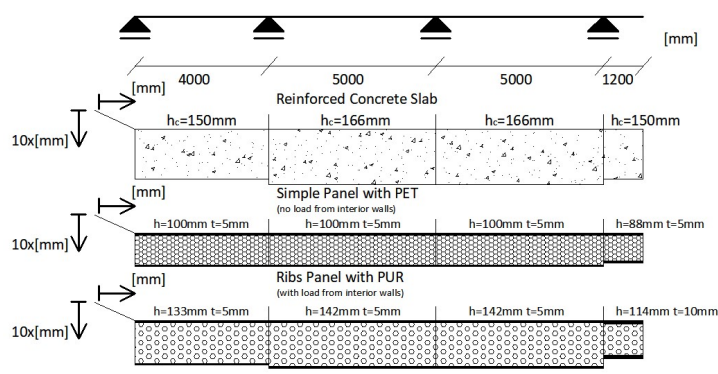

Fig. 9. Pre-design of the concrete slab and GFRP panel, for each span separately

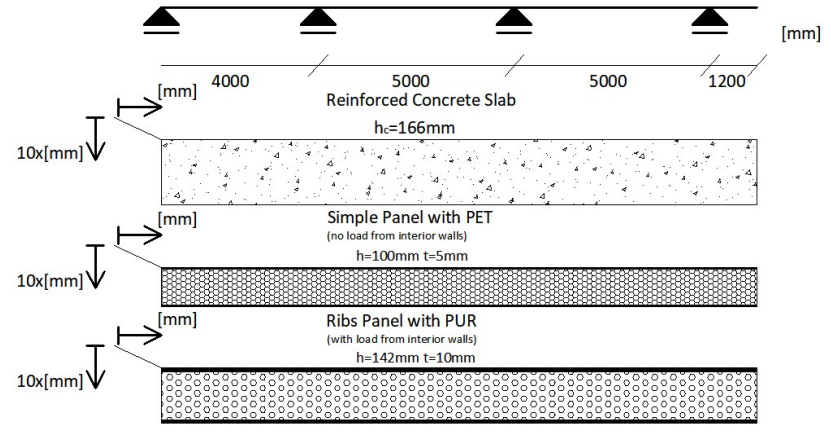

Fig. 10. Adopted pre-design geometry for the concrete slab and GFRP panel

\section{Conclusions and Further Developments}

When using CUF it is possible to promote a parametric campaign, in order to inquirer the minimum height of a given GFRP panel, so that vertical deflection due to creep, is below the limit allowed in the European structural codes. This was not possible with classical Timoshenko beam theory, since the shear correction factor is in general cases unknown. With this, it is possible to assemble a deflection control table for GFRP panel, just like the ones used in concrete slabs, in order to be used as pre-design guidelines for structural engineering in home buildings. Some assumptions/simplifications were adopted, but they were all conservative, therefore, it is expected that the vertical deflections are clearly below what was limited in the European structural codes. In the case study, it is possible to observe that the height of the GFRP panel is clearly competitive when compared with a classical concrete slab, even when using a SoftCore foam. This is extremely important, since the cost of manufacturing a GFRP panel is above a concrete slab.

\section{References}

Airex, AG_(3A Composites). (2016). Airex ${ }^{\circledR}$ T92 Easy Processing Structural Foam, Data Sheet 01.2016 (GF-TDS-021). http://www.airexbaltekbanova.com/airex-t92-pet-foam.html (accessed 29-03-2016).

Almeida, J.P.B.M, \& Freitas, J.A.T. (1991). Alternative approach to the formulation of hybrid equilibrium finite elements. Computer \& Structures, 40(4), 1043-1047.

Arruda, M. R. T., Castro, L. M. S., Ferreira, A. J. M., Garrido, M., Gonilha, J., \& Correia, J. R. (2018). Analysis of composite layered beams using Carrera unified formulation with Legendre approximation. Composites Part B: Engineering, 137(Supplement C), 39-50.

Arruda, M. R. T., Castro, L. M. S., Ferreira, A. J. M., Martins, D., \& Correia, J. R. (2018). Physically non-linear analysis of beam models using Carrera Unified Formulation. Composite Structures, 195, 60-73. doi: https://doi.org/10.1016/j.compstruct.2018.03.107

Arruda, M. R. T., Garrido, Mário, Castro, L. M. S., Ferreira, A. J. M., \& Correia, J. R. (2017). Numerical modelling of the creep behaviour of GFRP sandwich panels using the Carrera Unified Formulation and Composite Creep Modelling. Composite Structures, 183, 103-113.

Arruda, M.R., \& Castro, L.M.S.S. (2011). Structural dynamic analysis using hybrid and mixed finite element models. Finite Elements in Analysis and Design, 57, 43-57.

Bakis, C.E., Bank, L.C., Brown, V.L. , Cosenza, E., Davalos, J.F., Lesko, J.J., . . . Triantafillou, T.H. (2002). Fibre Reinforced Polymer Composites for Construction - State-of-the-Art Review. Journal of Composites for Construction, 6(2), 73-87.

Brockenbrough, R.L., \& Merritt, F.S. (1999). Structural steel designer's handbook. New York: McGrawHill.

Carrera, E. (2003). Theories and Finite Elements for Multilayered Plates and Shells: A Unified Compact Formulation with Numerical Assessment and Benchmarking. Archives of Computational Methods in Engineering, 10(3), 215-296.

Carrera, E., \& Boscolo, M. (2007). Classical and mixed finite elements for static and dynamic analysis of piezoelectric plates. International Journal for Numerical Methods in Engineering, 70, 11-35-1181. 
Carrera, E., \& Brischetto, S. (2008). Analysis of thickness locking in classical, refined and mixed multilayered plate theories. Composite Structures, 82(4), 549-562.

Carrera, E., Cinefra, M., Petrolo, M., \& Zappino, E. (2014). Finite Element Analysis of Structures through Unified Formulation. United Kingdom: Wiley.

Carrera, E., Giunta, G., Nali, P., \& Petrolo, M. (2010). Refined beam elements with arbitrary crosssection geometries. Computers \& Structures, 88(5-6), 283-293.

Carrera, E., Giunta, G., \& Petrolo, M.(2011). Beam Structures: Classical and Advanced Theories. United Kingdom: Wiley.

Carrera, E., Petrolo, M., \& Nali, P. (2011). Unified Formulation Applied to Free Vibrations Finite Element Analysis of Beams with Arbitrary Section. Shock and Vibration, 18(3). doi: 10.3233/sav2010-0528

Carrera, Erasmo, \& Ciuffreda, Angelo. (2005). Bending of composites and sandwich plates subjected to localized lateral loadings: a comparison of various theories. Composite Structures, 68(2), 185-202.

Carrera, Erasmo, Pagani, Alfonso, \& Petrolo, Marco. (2015). Refined 1D Finite Elements for the Analysis of Secondary, Primary, and Complete Civil Engineering Structures. Journal of Structural Engineering, 141(4), 04014123. doi: doi:10.1061/(ASCE)ST.1943-541X.0001076

Carrera, Erasmo, \& Petrolo, Marco. (2010). On the Effectiveness of Higher-Order Terms in Refined Beam Theories. Journal of Applied Mechanics, 78(2), 021013-021013. doi: 10.1115/1.4002207

Carrera, Erasmo, \& Petrolo, Marco. (2012). Refined beam elements with only displacement variables and plate/shell capabilities. Meccanica, 47(3), 537-556. doi: 10.1007/s11012-011-9466-5

Carrera, Erasmo, Petrolo, Marco, \& Varello, Alberto. (2012). Advanced Beam Formulations for FreeVibration Analysis of Conventional and Joined Wings. Journal of Aerospace Engineering, 25(2), 282293.

CEN/TC250. (2017). DRAF - Fibre Reinforced Polymer Structures. In E. C. f. Standardization (Ed.), Working Group 4 Scientific and Technical Report. Brussels.

Clickhouse. (2014). I\&D Clickhouse/ADI, project $n^{\circ}$ 2014/38967 co-financed by the European Union (FEDER) and COMPETE through (POFC).

Clough, R. W. (1960). Finite Element Method in Plane Stress Analysis. Paper presented at the Proceedings of $2^{\text {nd }}$ ASCE Conference on Electronic Computation, Pittsburgh.

CNR-DT-205/2007. (2008). Guide for the Design and Construction of Structures made of FRP Pultruded Elements. Italy: Advisory Committee on Technical Recommendations for Construction

Cook, R.D, Malkus, D.S. , Plesha, M.E., \& R.J., Witt. (2002). Concepts and Applications of Finite Element Analysis. USA: John Wiley and Sons Inc.

D7250M-16, ASTM D7250 /. (2016). Standard Practice for Determining Sandwich Beam Flexural and Shear Stiffness. In A. International (Ed.), West Conshohocken, . PA.

Davalos, J.F., Qiao, P., Xu, X.F., Robinson, J., \& Barth, K.E. (2001). Modeling and characterization of fibre-reinforced plastic honeycomb sandwich panels for highway bridge applications. Composite Structures, 52, 441-452.

EC1. (2002). Eurocode 1: Actions on Structures Part 1-1. Europe: EN1991-1-1.

EC2. (2010). Eurocode Design of concrete structures Part 1-1. Europe: EN1992-1-1.

Felippa, C.A. (2005). The Amusing History of Shear Flexible Beam Elements. Center for Aerospace Structures: College of Engineering University of Colorado Campus Box 429 Boulder Colorado 80309.

Ferreira, A.J.M., Araújo, A.L., Neves, A.M.A, Rodrigues, J.D., Carrera, E., Cinefra, M., . . . Fam, A. (2013). A finite element model using a unified formulation for the analysis of viscoelastic sandwich laminates. Composites: Part B, 45, 1258-1264.

Ferreira, A.J.M., Carrera, E., Cinefra, M., \& Roque, C.M.C. (2013). Radial basis functions collocation for the bending and free vibration analysis of laminated plates using the Reissner-Mixed Variational Theorem. European Journal of Mechanics A/Solids, 39, 104-112.

FIB. (2010). The fib Model Code 2010 for Concrete Structures, Model Code. International Federation for Structural Concrete. In E. Sohn (Ed.). Switzerland, Lausanne: FIB.

Fridley, Kenneth J., Pollock, Jr David G., \& Cobeen, Kelly. (2006). Design Of Wood StructuresAsd/Lrfd. 2nd Edition. 
Garrido, M., Madeira, J. F. A., Proença, M., \& Correia, J. R. (2019). Multi-objective optimization of pultruded composite sandwich panels for building floor rehabilitation. Construction and Building Materials, 198, 465-478. doi: https://doi.org/10.1016/j.conbuildmat.2018.11.259

Garrido, M.A. (2016). Composite sandwich panel floors for building rehabilitation. (Ph.D Thesis), Instituto Superior Técnico.

Garrido, M.A., Correia, J.R., Branco, F.A., \& Keller, T. (2014). Creep behaviour of sandwich panels with rigid polyurethane foam core and glass-fibre reinforced polymer faces: Experimental tests and analytical modelling. Journal of Composite Materials, 47(19).

Garrido, M.A., Correia, J.R., Branco, F.A., \& Sá, M.F. (2012). Creep behavior of GFRP sandwich panels for civil engineering structural applications. Paper presented at the 6th International Conference on FRP Composites in Civil Engineering - CICE 2012, Roma.

Garrido, Mário, \& Correia, João R. (2016). Elastic and viscoelastic behaviour of sandwich panels with glass-fibre reinforced polymer faces and polyethylene terephthalate foam core. Journal of Sandwich Structures and Materials. doi: 10.1177/1099636216657388

Garrido, Mário, Correia, João R., \& Keller, Thomas. (2016). Effect of service temperature on the shear creep response of rigid polyurethane foam used in composite sandwich floor panels. Construction and Building Materials, 118, 235-244.

Garrido, Mário, Correia, João R., Keller, Thomas, \& Cabral-Fonseca, Susana. (2016). Creep of Sandwich Panels with Longitudinal Reinforcement Ribs for Civil Engineering Applications: Experiments and Composite Creep Modeling. Journal of Composites for Construction, 04016074.

Ghali, A., Favre, R., \& Elbadry, M. (2018). Concrete Structures: Stresses and Deformations: Analysis and Design for Serviceability, Third Edition (3rd Edition ed.): CRC Press.

Ghali, A., \& Nevillle, A.M. (1997). Structural Analysis: A unified Classic and Matrix Approach. London: E \& FN Spon.

Giunta, G., Belouettar, S., \& Carrera, E. (2010). Analysis of FGM Beams by Means of Classical and Advanced Theories. Mechanics of Advanced Materials and Structures, 17(8), 622-635.

Gonilha, José A., Barros, Joaquim, Correia, João R., Sena-Cruz, José, Branco, Fernando A., Ramos, Luís F., . . . Santos, Tomé. (2014). Static, dynamic and creep behaviour of a full-scale GFRP-SFRSCC hybrid footbridge. Composite Structures, 118, 496-509.

Gonilha, José A., Correia, João R., \& Branco, Fernando A. (2014). Structural behaviour of a GFRPconcrete hybrid footbridge prototype: Experimental tests and numerical and analytical simulations. Engineering Structures, 60(0), 11-22. doi: http://dx.doi.org/10.1016/j.engstruct.2013.12.018

Hughes, T.J.R. (2003). The Finite Element Method", Linear Static and Dynamic Finite Element Analysis: Dover.

Kant, T., Owen, D.R.L., \& Zienkiewicz, O.C. (1982). A refined higher-order $\mathrm{C}^{0}$ plate bending element. Computer \& Structures, 30, 177-183.

Keller, T. (2008). Function integrated GFRP sandwich roof structure - Structural concept and design. Paper presented at the In Fourth International Conference on FRP Composites in Civil Engineering (CICE2008), Zurich Switzerland.

Keller, T., Vallée, T., \& Murcia, J. (2008). Function-integrated GFRP sandwich roof structure Experimental validation of design.

Leong, M., Lars C.T. Overgaard, L.C.T, Thomsen, T.O., Lund, E., \& Daniel, I.M. (2012). Investigation of failure mechanisms in GFRP sandwich structures with face sheet wrinkle defects used for wind turbine blades. Composite Structures, 94, 768-778.

Mase, G.T., \& Mase, G.E. (1999). Continuum Mechanics for Engineers. United States of America: CRC Press LLC.

Mucichescu, Dan T. (1984). Bounds for Stiffness of Prismatic Beams. Journal of Structural Engineering, 110(6), 1410-1414. doi: doi:10.1061/(ASCE)0733-9445(1984)110:6(1410)

Neves, A. M. A., Ferreira, A. J. M., Carrera, E., Roque, C. M. C., Cinefra, M., Jorge, R. M. N., \& Soares, C. M. M. (2012). A quasi-3D sinusoidal shear deformation theory for the static and free vibration analysis of functionally graded plates. Composites Part B: Engineering, 43(2), 711-725.

Novozhilov, VV. (1961). Theory of elasticity Pergamon. 
Pandya, B.N., \& Kant, T. (1988). Higher-order shear deformable theories for flexure of sandwich platesfinite element evaluations. international Journal of Solids and Structures, 24, 419-451.

Pereira, E.M.B.R. (1993). Elementos Finitos de Tensão, Aplicação à Análise Elástica de Estruturas. (Ph.D Thesis), Instituto Superior Técnico, Lisboa.

Pereira, E.M.B.R., \& Freitas, J.A.T. (1996a). A Hybrid-mixed Element Model Based on Legendre Polynomials for Reissner-Mindlin Plates. Computer Methods in Applied Mechanics and Engineering, 136(1-2), 111-126.

Pereira, E.M.B.R., \& Freitas, J.A.T. (1996b). A Mixed-Hybrid Finite Element Model based on Orthogonal Functions. International Journal for Numerical Methods in Engineering, 39(8), 12951312.

Reddy, J.N. (1984). A simple higher-order theory for laminated composite plates,. Journal of Applied Mechanics, 51(745-752).

Reddy, J.N. (1997). Mechanics of Laminated Composite Plates and Shells: Theory and Analysis. London: CRC Press.

Reddy, J.N. (1999). Theory and Analysis of Elastic Plates (Vol. 1). United States of America: Taylor \& Francis.

Reddy, J.N. (2004). An Introduction to Nonlinear Finite Element Analysis. Oxford: Oxford University press.

Reis, E.M., \& Rizkalla, S.H. (2008). Material characteristics of 3-D FRP sandwich panels. Construction and Building Materials, 22, 1009-1018.

Sá, Mário F., Gomes, Augusto M., Correia, João R., \& Silvestre, Nuno. (2016). Flexural creep response of pultruded GFRP deck panels: Proposal for obtaining full-section viscoelastic moduli and creep coefficients. Composites Part B: Engineering, 98, 213-224. doi: https://doi.org/10.1016/j.compositesb.2016.05.026

Sharaf, T., \& A., Fam. (2008). Flexural load tests on sandwich wall panels with different rib configurations. Paper presented at the In Fourth International Conference on FRP Composites in Civil Engineering (CICE2008), Zurich.

Silvestre, N., \& Camotim, D. (2002a). First-order generalised beam theory for arbitrary orthotropic materials. Thin-Walled Structures, 40(9), 755-789.

Silvestre, N., \& Camotim, D. (2002b). Second-order generalised beam theory for arbitrary orthotropic materials. Thin-Walled Structures, 40(9), 791-820.

Spiegel, R.M., \& Liu, J. (1999). Schaum's Mathematical Handbook of Formulas and Tables. New York: Schaum McGraw-Hill.

Timoshenko, S.P., \& Goodier, J.N. (1970). Theory of Elasticity. Tóquio: McGraw Hill International Book Company.

Timoshenko, S.P., \& Young, D.H. (1965). Theory of Structures. New York: McGraw-Hill.

Turner, M.J., Clough, R. W, Martin, H.C., \& Topp, L.J. (1956). Stiffness and Deflection Analysis of Complex Structures. Journal of The Aeronautical Sciences, 23(9), 805-823.

Zienkiewicz, O.C., \& Taylor, R.L. (2000). The Finite Element Method: For Solids and Structural Mechanics (Vol. 2). Londres: B-H.

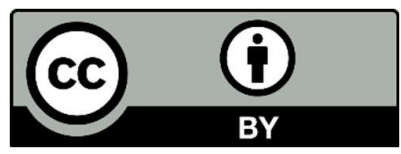

(C) 2020 by the authors; licensee Growing Science, Canada. This is an open access article distributed under the terms and conditions of the Creative Commons Attribution (CC-BY) license (http://creativecommons.org/licenses/by/4.0/). 